\title{
BJMHR
}

British Journal of Medical and Health Research

Journal home page: www.bjmhr.com

\section{Effect of Spicy Fast Foods and Red Chili Powder on Liver Status of Hypercholesterolemic Rats}

\author{
Hassan M. Bukhari ${ }^{1}$, Eslam A. Header ${ }^{1,2}$, Osama A. Shaikhomar ${ }^{3}$, Samah A. \\ Alharbi ${ }^{3}$ \\ 1. Department of Clinical Nutrition, Faculty of Applied Medical Sciences, UQU, Saudi \\ Arabia. \\ 2. Department of Nutrition and Food Science, Faculty of Home Economics, Menofia \\ University, Egypt. \\ 3. Department of Physiology, Faculty of Medicine, Umm Al-Qura University, Makkah, \\ Saudi Arabia.
}

\section{ABSTRACT}

Young Saudi adults largely consume spicy fast food. Studies indicate chilies reduce cardiovascular diseases (CVD) and lipid profiles. The present study investigated the effect of spicy Saudi Arabian fast foods on liver status of hypercholesterolemic rats. Seventy male rats were equally divided into seven groups, all fed standard diets with or without modification. Negative controls were fed standard diet only, while the other six groups were fed an additional $2 \%$ cholesterol for 2 weeks to induce hypercholesterolemia. Then, three hypercholesterolemic groups were fed different doses of red chili (RC) extract (150, 300, and $600 \mathrm{mg} / \mathrm{kg}$ body weight), two were fed $30 \%$ broasted chicken or deep fried chicken nuggets of SD, and one remained on standard diet only (positive control). Compared to the positive control, all groups showed significant changes in lipid profiles except for very-low-density lipoprotein. All RC doses lowered cholesterol and low density lipoprotein levels relative to positive controls. However, those fed broasted chicken had a larger reduction in lipid profile ratios than RC groups. Nonetheless, $600 \mathrm{mg} / \mathrm{kg}$ of $\mathrm{RC}$ had the greatest impact on lowering lipid ratios. Moreover, high doses of RC extract lowered glucose, alkaline phosphatase, glutamate pyruvate transaminase, and glutamic-oxaloacetic transaminase levels the most. Spicy chicken elevated levels of those markers compared to RC groups. Yet, there is lowering trend goes opposite to doses of RC extracts in all liver functions. In conclusion, RC powder mixed with nonfatty food have a better effect on liver functions than consumption of RC in fatty, fried food. Although not advised, if the consumption of fast food is continued, adding $\mathrm{RC}$ is suggested as it could help lower the risk of CVD.

Keywords: red chilies, liver, hypercholesteremia, nuggets, chicken, spicy food 


\section{INTRODUCTION}

Traditional Saudi cuisine merges several international food patterns, particularly in main cities and communities with different ethnicities. Major and important influence comes from subcontinental Asian countries and Far East foods, as well as Western style dishes with strong flavors, spices, and ingredients ${ }^{1}$. Although food patterns nowadays are far from healthy, many dishes are rich in chilies and spices, and a high percentage of the Saudi population, including young adults and teenagers, have gotten used to adding extra chilies to many meals consumed on a regular basis ${ }^{2,3}$. Recently, consumption of fast food with mixed spices has increased dramatically in Saudi Arabia. Recent studies have shown that consumption of chilies and other spices has increased double or more per capita ${ }^{2,4}$.

Almost all nutritional guidelines for a healthy diet recommend moderate consumption of a variety of items from multiple food groups and items, including food spices. For centuries, chilies and hot spices have been known to have medicinal and healing properties. Studies have indicated the health benefits of chilies and other spices include a reduction of cancer incidence rate, appetite and obesity, and cardiovascular diseases [CVD] ${ }^{5,6}$. In a human study, daily consumption of spices and chilies has been shown to contribute to a reduction in mortality rates in China associated with an inverse relationship between chili consumption and CVD, respiratory infections, and many cancers ${ }^{7}$. A mechanism by which hot chilies are suggested to exert their beneficial effects is through the main active constituent capsaicin, which has been shown to reduce cholesterol, triglyceride, and low-density lipoprotein (LDL) levels, leading to a reduction in liver damage ${ }^{8,9}$. The present study evaluated the effect of Saudi Arabian red chilies (RC) on liver status of hypercholesterolemic rats.

\section{MATERIALS AND METHOD}

\section{Animals and diets}

Samples of commercially made RC powder (Capsicum frutescens) and broasted chicken and deep fried chicken nuggets with RC pepper already integrated into the preparation were used. All of these foods were purchased from a local market in Makkah, Saudi Arabia. According to standard cooking methods and ingredients, $100 \mathrm{~g}$ of nuggets or broasted chicken prepared yields 300 or $600 \mathrm{mg}$ of RC ${ }^{10,11}$.

Seventy male albino Sprague Dawley rats (185 $\pm 8 \mathrm{~g}$ each) were obtained from the Laboratory Animal Centre, Department of Biochemistry, Faculty of Medicine, Umm Al-Qura University (Makkah, Saudi Arabia). All animals were fed a standard diet consisting of casein (12.5\%), corn oil $(10 \%)$, choline chloride $(0.2 \%)$, vitamin mixture $(1 \%)$, cellulose $(5 \%)$, salt mixture (4\%), sucrose (22\%), and corn starch (up to $100 \%$ ) according to the National Research Council ${ }^{12}$. Then, they were divided into seven dietary groups ( $n=10$ per group): negative control group 
rats were fed standard diet only, while the other six groups received an additional $2 \%$ cholesterol for 2 weeks to induce hypercholesterolemia. Of the six hypercholesterolemic groups, one served as the positive control and remained on standard diet only, three were fed standard diet with different doses of RC powder extract [150, 300, or $600 \mathrm{mg} / \mathrm{kg}$ body weight 13 added, and two were fed standard diets with $30 \%$ broasted chicken or nuggets of SD. All procedures described were reviewed and approved by the Animal Care and Use Bioethical Committee of Medical Sciences, Umm Al-Qura University.

\section{Blood collection and fat measurement}

At the end of 8 weeks and $24 \mathrm{~h}$ after the last feeding, blood samples were collected by euthanizing all rats in a chamber containing diethyl ether. Two blood samples were collected from each animal into a heparin containing and plane tube. For serum collection, blood samples in plane tubes were centrifuged at $3000 \mathrm{rpm}$ for $10 \mathrm{~min}$.

\section{Biochemical measures}

Triglycerides and cholesterol were measured with enzymatic kits ${ }^{14,}{ }^{15}$. High-density lipoprotein (HDL)-cholesterol (HDLC) was determined according to previous methods ${ }^{16,17}$. The very-low-density lipoprotein (VLDL)-cholesterol (VLDLC) and LDL-cholesterol (LDLC) concentrations were calculated from the Reitman and Frankel equations [18]: LDLC $=$ Total Cholesterol - $($ HDLC + VLDLC $)$ and VLDLC $=$ Triglycerides/5. Various enzymatic colorimetric methods were used to determine blood glucose ${ }^{19}$, aspartate aminotransferase and alanine aminotransferase ${ }^{18}$, alkaline phosphatase (ALP) activity ${ }^{20}$, and total protein ${ }^{21}$.

\section{Statistical analysis}

Data were expressed as means \pm standard errors of 10 experiments. In order to compare groups, analysis of variance was used. A paired-sample Student's $t$-test was used to compare parameters between the positive control and other hypercholesterolemic groups. A $P<0.05$ was considered statistically significant using the SPSS version 20 for windows.

\section{RESULTS AND DISCUSSION}

\section{Effect of RC on liver-to-body weight ratio}

Table 1 shows that only rats fed $600 \mathrm{mg} / \mathrm{kg}$ RC powder extract exhibited a significant liver-tobody weight ratio change compared to the positive control $(P<0.002)$, while all other groups did not. 
Table 1: Effect of red chilies (RC) on liver-to-body weight ratio.

\begin{tabular}{|c|c|c|c|}
\hline \multirow[t]{2}{*}{ Groups } & \multirow[t]{2}{*}{ Mean \pm SE } & \multicolumn{2}{|c|}{ ANOVA } \\
\hline & & $F$ & Sig. \\
\hline $\mathrm{G} \mathrm{I}\left(\mathrm{C}^{-}\right)$ & $2.15 \pm 0.086$ & 4.6 & 0.002 \\
\hline \multirow[t]{2}{*}{$\mathrm{G}$ II $\left(\mathrm{C}^{+}\right)$} & $2.85 \pm 0.31$ & & \\
\hline & $2.85 \pm 0.139$ & & \\
\hline G IV RC 300 mg/kg & $2.74 \pm 0.090$ & & \\
\hline G V RC $600 \mathrm{mg} / \mathrm{kg}$ & $2.7 \pm 0.081^{*}$ & & \\
\hline G VI $30 \%$ Chicken of SD & $3.25 \pm 0.306$ & & \\
\hline G VII $30 \%$ Negates of SD & $3.48 \pm 0.188$ & & \\
\hline $\begin{array}{l}\text { Positive control was comp } \\
<0.05 \text {. SE, standard error; }\end{array}$ & $\begin{array}{l}\text { to all other } h \\
\text { sis of varianc }\end{array}$ & rolen & roups. ${ }^{*} P$ \\
\hline
\end{tabular}

\section{Effect of RC on lipid profiles}

Table 2 shows significant changes in cholesterol, HDLC, and LDL levels ( $P<0.05$ or 0.01$)$ in rats fed 150, 300, and $600 \mathrm{mg} / \mathrm{kg} \mathrm{RC}$ groups compared with negative controls; however, HDLC levels did not change significantly for the $150 \mathrm{mg} / \mathrm{kg}$ RC group. Rats fed $30 \%$ broasted chicken or nuggets also showed a significant change in HDLC $(P<0.05)$ compared to positive controls, whereas cholesterol, triglyceride, VLDL, and LDL levels did not change significantly in any groups.

Table 2: Effect of red chilies (RC) on lipid profiles.

\begin{tabular}{llllll}
\hline Groups & $\begin{array}{l}\text { Cholesterol } \\
(\mathbf{m g} / \mathbf{d L})\end{array}$ & $\begin{array}{l}\text { Triglycerides } \\
(\mathbf{m g} / \mathbf{d L})\end{array}$ & $\begin{array}{l}\text { HDLC } \\
(\mathbf{m g} / \mathbf{d L})\end{array}$ & $\begin{array}{l}\text { VLDL } \\
\text { (mg/dL) }\end{array}$ & $\begin{array}{l}\text { LDL } \\
(\mathbf{m g} / \mathbf{d L})\end{array}$ \\
& Mean \pm SE & Mean \pm SE & Mean \pm SE & Mean \pm SE & Mean \pm SE \\
\hline G I (C $\left.)^{-}\right)$ & $189.6 \pm 5.7^{* * *}$ & $146.6 \pm 11.6^{* *}$ & $80.04 \pm 1.79^{* *}$ & $29.33 \pm 2.32$ & $80.23 \pm 4.22^{* * *}$ \\
G II (C $)$ & $255.2 \pm 10.1$ & $225.8 \pm 7.31$ & $52.56 \pm 4.43$ & $45.17 \pm 3.46$ & $157.4 \pm 9.71$ \\
G III RC 150 & $202.1 \pm 10.9^{* *}$ & $195.4 \pm 11.68$ & $64.56 \pm 7.99$ & $39.07 \pm 6.34$ & $98.38 \pm 7.59^{* *}$ \\
G IV RC 300 & $200.8 \pm 8.1^{* *}$ & $186.6 \pm 6.79$ & $71.00 \pm 3.45^{*}$ & $37.32 \pm 1.36$ & $92.55 \pm 7.74^{* *}$ \\
G V RC 600 & $186.3 \pm 4.3^{* *}$ & $195.1 \pm 4.34$ & $75.06 \pm 2.13^{* *}$ & $39.03 \pm 2.87$ & $72.23 \pm 3.38^{* *}$ \\
G VI 30\% & $209.4 \pm 9.4$ & $193.9 \pm 4.36$ & $76.04 \pm 3.55^{*}$ & $38.79 \pm 2.87$ & $94.52 \pm 7.58$ \\
Chicken & & & & & \\
G VII 30\% & $228.3 \pm 5.7$ & $205.9 \pm 5.56$ & $78.16 \pm 5.69^{*}$ & $41.17 \pm 5.11$ & $108.9 \pm 7.17$ \\
Nuggets & & & & & \\
ANOVA & & & & & \\
F & 6.112 & 1.575 & 4.380 & 1.576 & 9.111 \\
Sig. & 0.001 & 0.191 & 0.003 & 0.191 & 0.001
\end{tabular}

Data expressed as means \pm standard errors; $* P<0.05, * * P<0.01$. Positive control was compared statistically to all other hypercholesterolemic groups. ANOVA, analysis of variance; HDLC, high-density lipoprotein-cholesterol; VLDL, very-low-density lipoprotein-cholesterol; LDL, low-density lipoprotein

\section{Atherogenic index after $\mathrm{RC}$ ingestion}

Table 3 shows a significant change in LDL/HDL ratio for rats fed 300 and $600 \mathrm{mg} / \mathrm{kg} \mathrm{RC}(P$ $<0.01)$ as well as $30 \%$ broasted chicken or nuggets $(P<0.05)$ compared to the positive control; however, the $150 \mathrm{mg} / \mathrm{kg} \mathrm{RC}$ group did not show a significant change. In addition, the TC/LDL ratio showed significant changes for 150,300 , and $600 \mathrm{mg} / \mathrm{kg} \mathrm{RC}$ and $30 \%$ broasted chicken 
group $(P<0.05$ or 0.01$)$. The $30 \%$ nugget group showed no significant change. Finally, the TC/HDL ratio significantly changed for 300 and $600 \mathrm{mg} / \mathrm{kg} \mathrm{RC}$ and $30 \%$ broasted chicken $(P$ $<0.05$ or 0.01 ), while $150 \mathrm{mg} / \mathrm{kg} \mathrm{RC}$ and $30 \%$ nugget groups showed no significant change.

Table 3: Atherogenic index after red chili (RC) ingestion.

\begin{tabular}{|c|c|c|c|}
\hline Groups & $\begin{array}{l}\text { LDL/HDL } \\
\text { Mean } \pm \text { SE }\end{array}$ & $\begin{array}{l}\text { TC/LDL } \\
\text { Mean } \pm \text { SE }\end{array}$ & $\begin{array}{l}\text { TC/HDL } \\
\text { Mean } \pm \text { SE }\end{array}$ \\
\hline $\mathrm{G} \mathrm{I}\left(\mathrm{C}^{-}\right)$ & $1.00 \pm 0.039^{* *}$ & $2.37 \pm 0.060^{* *}$ & $2.37 \pm 0.055^{* *}$ \\
\hline G II $\left(\mathrm{C}^{+}\right)$ & $3.07 \pm 0.307$ & $1.63 \pm 0.055$ & $4.95 \pm 0.357$ \\
\hline G III RC 150 & $1.67 \pm 0.312$ & $2.09 \pm 0.137^{*}$ & $3.32 \pm 0.406$ \\
\hline G IV RC 300 & $1.32 \pm 0.137^{* *}$ & $2.20 \pm 0.092^{*}$ & $2.85 \pm 0.166^{* *}$ \\
\hline G V RC 600 & $0.96 \pm 0.045^{* *}$ & $2.6 \pm 0.110^{* *}$ & $2.47 \pm 0.017^{* *}$ \\
\hline G VI 30\% Chicken & $1.24 \pm 0.066^{*}$ & $2.24 \pm 0.084^{*}$ & $2.76 \pm 0.085^{*}$ \\
\hline G VII 30\% Nuggets & $1.44 \pm 0.292^{*}$ & $2.19 \pm 0.145$ & $2.99 \pm 0.339$ \\
\hline \multicolumn{4}{|l|}{ ANOVA } \\
\hline $\mathbf{F}$ & 12.001 & 8.287 & 11.986 \\
\hline Sig. & 0.001 & 0.001 & 0.001 \\
\hline \multicolumn{4}{|c|}{$\begin{array}{l}\text { Data expressed as means } \pm \text { standard errors; } * P<0.05, * * P<0.01 \text {. Positive } \\
\text { control was compared statistically to all other hypercholesterolemic groups. } \\
\text { ANOVA, analysis of variance; LDL, low-density lipoprotein; HDL, high- } \\
\text { density lipoprotein; TC, total cholesterol }\end{array}$} \\
\hline
\end{tabular}

\section{Effect of RC on liver function}

Table 4 shows there was no significant change in glucose levels for RC 150 and $300 \mathrm{mg} / \mathrm{kg}$ $\mathrm{RC}$ and $30 \%$ broasted chicken and nugget groups, while $600 \mathrm{mg} / \mathrm{kg} \mathrm{RC}$ showed a significant change $(P<0.05)$. The same results were found for ALP and glutamate pyruvate transaminase. Other the other hand, no significant change in total protein was observed for any group. For glutamic-oxaloacetic transaminase (GOT), a significant change was observed for 300 and 600 $\mathrm{mg} / \mathrm{kg} \mathrm{RC}(P<0.05)$, but not for $150 \mathrm{mg} / \mathrm{kg} \mathrm{RC}$ or $30 \%$ broasted chicken or nugget groups.

Table 4: Effect of red chilies (RC) on liver function.

\begin{tabular}{|c|c|c|c|c|c|}
\hline Groups & $\begin{array}{l}\text { Glucose } \\
\mathrm{mg} / \mathrm{dL} \\
\text { Mean } \pm \mathrm{SE}\end{array}$ & $\begin{array}{l}\text { T. protein } \\
\text { g/dL } \\
\text { Mean } \pm \text { SE }\end{array}$ & $\begin{array}{l}\text { ALP } \\
\text { U/L } \\
\text { Mean } \pm \text { SE }\end{array}$ & $\begin{array}{l}\text { GPT } \\
\text { U/L } \\
\text { Mean } \pm \text { SE }\end{array}$ & $\begin{array}{l}\text { GOT } \\
\text { U/L } \\
\text { Mean } \pm \text { SE }\end{array}$ \\
\hline $\mathrm{G} \mathrm{I}\left(\mathrm{C}^{-}\right)$ & $87.69 \pm 4.95^{* *}$ & $6.80 \pm 0.412$ & $222.4 \pm 7.42^{* *}$ & $30.38 \pm 2.9^{* *}$ & $31.45 \pm 5.2^{*}$ \\
\hline $\mathrm{G}$ II $\left(\mathrm{C}^{+}\right)$ & $134.9 \pm 18.29$ & $8.35 \pm 1.172$ & $585.3 \pm 45.16$ & $48.70 \pm 0.768$ & $44.44 \pm 0.864$ \\
\hline G III RC 150 & $107.8 \pm 12.14$ & $8.06 \pm 0.889$ & $424.4 \pm 82.75$ & $41.81 \pm 5.322$ & $32.41 \pm 4.513$ \\
\hline G IV RC 300 & $104.9 \pm 17.24$ & $9.18 \pm 0.636$ & $424.1 \pm 54.41$ & $34.79 \pm 5.06$ & $30.51 \pm 5.41^{*}$ \\
\hline G V RC 600 & $92.1 \pm 16.59^{*}$ & $8.6 \pm 2.147$ & $373.3 \pm 31.51^{*}$ & $29.45 \pm 2.78^{* *}$ & $25.73 \pm 2.5^{* *}$ \\
\hline G VI 30\% Chicken & $129.4 \pm 20.27$ & $9.54 \pm 0.963$ & $512.6 \pm 68.68$ & $49.60 \pm 0.678$ & $45.10 \pm 1.018$ \\
\hline $\begin{array}{l}\text { G VII } 30 \% \text { Nuggets } \\
\text { ANOVA }\end{array}$ & $122.0 \pm 30.42$ & $8.45 \pm 1.778$ & $390.6 \pm 95.74$ & $48.40 \pm 0.927$ & $44.04 \pm 1.181$ \\
\hline $\mathbf{F}$ & 0.957 & 0.471 & 3.400 & 7.676 & 5.281 \\
\hline Sig. & 0.471 & 0.824 & 0.012 & 0.001 & 0.001 \\
\hline
\end{tabular}

Data expressed as means \pm standard errors; $* P<0.05,{ }^{*} * P<0.01$. Positive control was compared statistically to all other hypercholesterolemic groups. ANOVA, analysis of variance; ALP, alkaline phosphatase; GPT, glutamate pyruvate transaminase; GOT, glutamic-oxaloacetic transaminase 


\section{DISCUSSION:}

Spicy foods have been consumed by many cultures for over 4000 years. Traditional Chinese and Indian cuisines are famous for spicy dishes. In Saudi Arabia, consumption of spicy foods has increased over the years, especially in fried fast foods. The present study evaluated the effect of RC powder extract on a standard diet or combined with deep-fried fast food on hypercholesterolemic rat models. Studies around the globe have shown conflicting effects of red pepper or chilies on health ${ }^{22}$, particularly with respect to liver damage ${ }^{8}$. Nonetheless, there is much evidence supporting their beneficial effect on the function and structure of various tissues and organs in humans and animals, as in the current study. In fact, the main active constituent in hot chilies, capsaicin, has been shown to affect lipid profiles and reduce liver damage ${ }^{8,9,23,24}$. Herein, RC powder extract mixed with a standard diet had best effect on liver function and structure compared to deep fried food with RC integrated into the recipe.

While all groups that consumed RC had different liver weights than the positive control, only the highest dose of RC (600 mg/kg) offered a significant change. Likewise, Kim et al. ${ }^{9}$ also found a change in liver size in rats. The change in weight with $\mathrm{RC}$ consumption can be explained in the light of the fact that capsaicin has been shown to significantly decrease liver size by reducing hepatocyte inflammation as well as fat content. On the other hand, another study in rabbits reported the histopathological structure of cells showed an increase in the size of blood veins and fluid congestion, causing an increase in liver size ${ }^{25}$. In contrast, the size of livers in rats fed fast food containing RC in the present study were bigger than both negative and positive controls. The high fat content of deep fried fast food can increase insulin secretion, increasing fat stored in the liver.

Regarding lipid profiles, all groups in the current study show some changes relative to the positive control though not always significantly. However, VLDL levels did not differ much in any group compared to the positive control, in contrast to some previous studies ${ }^{26},{ }^{27}$. Here, addition of RC to the standard diet caused a significant concentration-dependent decrease in cholesterol and LDL but an increase in HDL. Furthermore, increases in cholesterol, LDL, VLDL, and a significant increase in HDL was observed with consumption of broasted chicken and nuggets compared to positive control. Similar findings have been reported previously ${ }^{25}$ ${ }^{27}$. Of note, the current study used much higher concentrations of RC than Al-Jumayi et al. ${ }^{25}$ [150-600 $\mathrm{mg} / \mathrm{kg}$ versus 5-10 $\mathrm{mg} / \mathrm{kg}$, respectively]. This difference between studies demonstrates two key points. First, that at higher doses, the beneficial effects of RC are even better, as long as the animal can tolerate it throughout the experimental period. Tolerance of $\mathrm{RC}$ ingestion is important as many animals and humans are not used to consuming moderate 
to higher doses of spice in foods ${ }^{28}$. Second, consumption of lower doses of RC may still be beneficial to some extent along with a healthy diet.

With respect to ingestion, bioavailability must be considered. Use of pure capsaicin would equate to a high dose compared to consumption of natural and complete RC peppers ${ }^{28}$. Likewise, fried food like nuggets and broasted chicken have many more components that could reduce the availability and activity of the capsaicin in $\mathrm{RC}$ even more so than components found in a healthy diet. This might explain the low/absence of effect of certain spicy foods on lipid profiles or other liver functions.

The anti-atherogenic effect of RC consumption found in the present study is encouraging as LDL/HDL and TC/HDL ratios were lower than the positive control, with only a slight increase in TC/LDL ratio. The greatest effect occurred with $600 \mathrm{mg} / \mathrm{kg}$ RC. Moreover, these significant, beneficial changes also occurred with consumption of spicy broasted chicken. These positive results are similar to those found in previous studies ${ }^{26,29}$. Importantly, the poor LDL/HDL ratio, which increases the risk of CVD, exhibited by the positive control was lowered significantly by consumption of RC as part of a standard diet or in fast food. Such RC effects could be the result of various mechanisms, such as the activation effect of capsaicin on hepatocytic cell receptors, like proliferator-activated receptor $\alpha$. At the physiological level, absorption of cholesterol could also be reduced in the intestine, with more cholesterol combining with bile salts and being excreted ${ }^{24,30,31}$.

In terms of liver function, the current study measured glucose, GOT, ALP, and glutamate pyruvate transaminase levels. Apart from total protein, all measures in all groups were significantly different from that of the positive control. However, $600 \mathrm{mg} / \mathrm{kg} \mathrm{RC}$ lowered glucose, ALP, glutamate pyruvate transaminase, and GOT levels the most. Al-Jumayi et al. ${ }^{25}$ reported the same effect, with lowered alanine aminotransferase, aspartate aminotransferase, and bilirubin compared to the control. Though they did not measure glucose levels, lowered glucose with RC consumption was also reported in rabbit models ${ }^{23}$. A reduction in glucose levels can be explained by inhibition of certain enzymes involved in glucose metabolism, like $\alpha$-amylase and $\alpha$-glucosidase ${ }^{32,33}$. Other mechanisms could be related to increased insulin sensitivity and improved glucose tolerance ${ }^{34}$.

\section{CONCLUSION:}

The current study found that consumption of enough RC with a standard/healthy diet or as ingredient of deep fried fast food has a positive effect on lipid profiles, reducing cholesterol, triglycerides, and LDL and increasing HDL, as well as liver function, decreasing glucose, GOT, and alanine aminotransferase. However, consumption of RC with a standard/healthy diet 
had the most beneficial effects. Thus, it is recommended that more RC powder be consumed with meals.

\section{ACKNOWLEDGMENTS:}

The authors thank the Institute of Scientific Research and Revival of Islam, Umm Al-Qura University, Makkah, Saudi Arabia and the Heritage for Research project fund (43109023).

\section{REFERENCES:}

1. M. Moradi-Lakeh et al., "The health of Saudi youths: Current challenges and future opportunities," BMC Fam. Pract., vol. 17, no. 1, pp. 26-26, Mar. 2016, doi: 10.1186/s12875-016-0425-z.

2. H. H. Al-Otaibi and A. M. Basuny, "Fast food consumption associated with obesity/overweight risk among university female student in Saudi Arabia," Pakistan J. Nutr., vol. 14, no. 8, pp. 511-516, 2015, doi: 10.3923/pjn.2015.511.516.

3. N. M. D. Al Moraie, "Dietary patterns in Saudi Arabian adults residing in different geographical locations in Saudi Arabia and in the UK in relation to heart disease risk," 2014, Accessed: Aug. 26, 2020. [Online]. Available: http://theses.ncl.ac.uk/jspui/handle/10443/2562.

4. A. Adam, S. Osama, and K. Ibrar Muhammad, "Nutrition and food consumption patterns in the Kingdom of Saudi Arabia," Pakistan J. Nutr., vol. 13, no. 4, pp. 181190, 2014, doi: 10.3923/pjn.2014.181.190.

5. B. Nilius and G. Appendino, "Spices: The savory and beneficial science of pungency," Rev. Physiol. Biochem. Pharmacol., vol. 164, pp. 1-76, 2013, doi: 10.1007/112_2013_11.

6. S. K. Sharma, A. S. Vij, and M. Sharma, "Mechanisms and clinical uses of capsaicin," European Journal of Pharmacology, vol. 720, no. 1-3. Eur J Pharmacol, pp. 55-62, Nov. 15, 2013, doi: 10.1016/j.ejphar.2013.10.053.

7. J. Lv et al., "Consumption of spicy foods and total and cause specific mortality: Population based cohort study," BMJ, vol. 351, Aug. 2015, doi: 10.1136/bmj.h3942.

8. M. A. Dkhil and S. Al-Quraishy, "Effects of extensive consumption of hot red pepper fruit on liver of rabbit," J. Med. Plants Res., vol. 4, no. 23, pp. 2533-2538, 2010, doi: 10.5897/jmpr10.497.

9. J. S. Kim, T. Y. Ha, S. Kim, S. J. Lee, and J. Ahn, "Red paprika (Capsicum annuum L.) and its main carotenoid capsanthin ameliorate impaired lipid metabolism in the liver and adipose tissue of high-fat diet-induced obese mice," J. Funct. Foods, vol. 31, pp. 131-140, Apr. 2017, doi: 10.1016/j.jff.2017.01.044.

10. MacDonald's, “website on Chicken nuggets," 2019 . . 
11. K. website on chicken Broast, "No Title," 2019. .

12. Nutrient Requirements of Laboratory Animals, . National Academies Press, 1995.

13. O. A. Shaikh Omar, H. M. Bukhari, N. A. Elsawy, and E. A. Header, "Efficacy of Capsicum Frutescens in Curing the Peptic Ulcer," 2013. Accessed: Aug. 26, 2020. [Online]. Available: www.ijopaasat.in.

14. C. C. Allain, "Cholesterol enzymatic colorimetric method," J. Clin. Chem., vol. 20, p. 470, 1974.

15. L. Young, D. and Pestaner, "Determination of triglycerides," Ger. J. Clin. Chem., vol. 21, p. 25, 1974.

16. W. T. Friedewald, "Determination of HDL," Clin. Chem., vol. 18, p. 499, 1972.

17. M. Gordon, T. and Amer, "Determination of HDL.," J. Med., vol. 62, p. 707, 1977.

18. S. Reitman, S. and Frankel, "Determination of serum glutamic oxaloacetic transaminase and serum pyruvic transaminase," Am. J. Chem. Path., vol. 28, pp. 56$68,1957$.

19. P. Trinder, "Determination of triglycerides," Ann. Clin. Biochem., vol. 6, pp. 24-27, 1969.

20. T. U. Haussament, "Determination of alkaline phosphatase," Clin. Chem. Acta, vol. 35, pp. 271-273, 1977.

21. G. A. Henry, J.B., Nelson, D.A., Tomar, R.H., Washington, J.A., and Threatth, "Clinical diagnosis management by laboratory methods," 18th Ed. W.B. Saunders Company, Harcourt Brace Jovanovich, Inc., 1991.

22. A. M. Bode and Z. Dong, "The Two Faces of Capsaicin," doi: 10.1158/00085472.CAN-10-3756.

23. M. F. McCarty, J. J. DiNicolantonio, and J. H. O'Keefe, “Capsaicin may have important potential for promoting vascular and metabolic health: Table 1," Open Hear., vol. 2, no. 1, p. e000262, Jun. 2015, doi: 10.1136/openhrt-2015-000262.

24. Q. Li et al., "Dietary capsaicin prevents nonalcoholic fatty liver disease through transient receptor potential vanilloid 1-mediated peroxisome proliferator-activated receptor $\delta$ activation," Pflugers Arch. Eur. J. Physiol., vol. 465, no. 9, pp. 1303-1316, Sep. 2013, doi: 10.1007/s00424-013-1274-4.

25. H. A. O. Al-Jumayi, H. A. Elhendy, and A. M. G. Darwish, "Biological effects of red chili pepper (Capsicum annuum) consumption on high fat diet female albino rats," Pakistan J. Biol. Sci., vol. 23, no. 2, pp. 150-158, 2020, doi: 10.3923/pjbs.2020.150.158.

26. S. Sanati, B. M. Razavi, and H. Hosseinzadeh, "A review of the effects of Capsicum annuum L. And its constituent, capsaicin, in metabolic syndrome," Iranian Journal of 
Basic Medical Sciences, vol. 21, no. 5. Mashhad University of Medical Sciences, pp. 439-448, May 01, 2018, doi: 10.22038/IJBMS.2018.25200.6238.

27. L. Zhang, M. Zhou, G. Fang, Y. Tang, Z. Chen, and X. Liu, "Hypocholesterolemic effect of capsaicinoids by increased bile acids excretion in ovariectomized rats," Mol. Nutr. Food Res., vol. 57, no. 6, pp. 1080-1088, Jun. 2013, doi: 10.1002/mnfr.201200716.

28. M. P. G. M. Lejeune, E. M. R. Kovacs, and M. S. Westerterp-Plantenga, "Effect of capsaicin on substrate oxidation and weight maintenance after modest body-weight loss in human subjects," Br. J. Nutr., vol. 90, no. 3, pp. 651-659, Sep. 2003, doi: 10.1079/bjn2003938.

29. A. Otunola, G., Oloyede, O., Oladiji, A., Afolayan, "Hypolipidemic effect of aqueous extracts of selected spices and their mixture on diet-induced hypercholesterolemia in Wistar rats," Can J Pure Appl. Sci; , vol. 6, pp. 2063-2071, 2012.

30. M. Mueller, V. Beck, and A. Jungbauer, "PPAR $\alpha$ activation by culinary herbs and spices," Planta Med., vol. 77, no. 5, pp. 497-504, 2011, doi: 10.1055/s-0030-1250435.

31. J. A. Negulesco, S. A. Noel, H. A. I. Newman, E. C. Naber, H. B. Bhat, and D. T. Witiak, "Effects of pure capsaicinoids (capsaicin and dihydrocapsaicin) on plasma lipid and lipoprotein concentrations of turkey poults," Atherosclerosis, vol. 64, no. 2-3, pp. 85-90, 1987, doi: 10.1016/0021-9150(87)90233-4.

32. “(PDF) The $\alpha$-glucosidase and $\alpha$-amylase inhibitory activity from different chili pepper extracts." https://www.researchgate.net/publication/305409686_The_aglucosidase_and_a-amylase_inhibitory_activity_from_different_chili_pepper_extracts (accessed Aug. 26, 2020).

33. R. Tundis et al., "Comparative Study on the Chemical Composition, Antioxidant Properties and Hypoglycaemic Activities of Two Capsicum annuum L. Cultivars (Acuminatum small and Cerasiferum)," Plant Foods Hum. Nutr., vol. 66, no. 3, pp. 261-269, Sep. 2011, doi: 10.1007/s11130-011-0248-y.

34. F. Sun, S. Xiong, and Z. Zhu, "Dietary capsaicin protects cardiometabolic organs from dysfunction," Nutrients, vol. 8, no. 5. MDPI AG, May 01, 2016, doi: 10.3390/nu8050174.

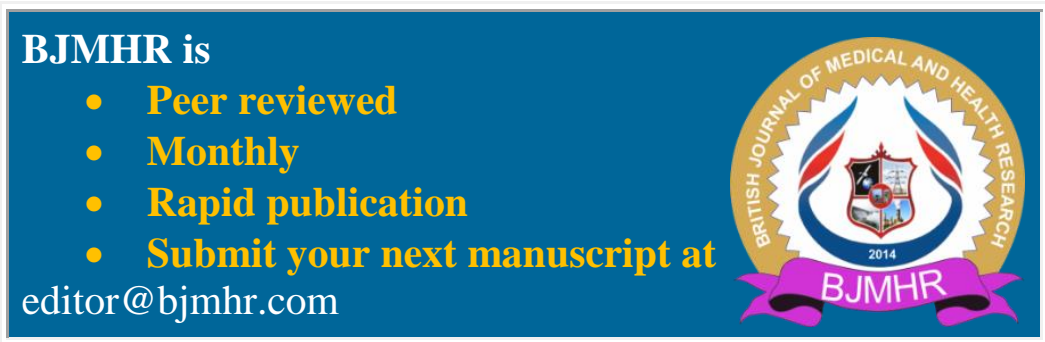

